\title{
Sinopse da família Cyperaceae em uma área do extremo sul do Rio Grande do Sul, Brasil
}

Synopsis of Cyperaceae family in an area of southernmost Rio Grande do Sul, Brazil

\author{
Amapola Corrêa Soares ${ }^{1}$, Jozeane Lopes Villar $^{1}$, Sonia Marisa Hefler ${ }^{1,2}$
}

\begin{abstract}
Resumo
Este trabalho foi baseado na análise de materiais de herbário, documentações bibliográficas e coletas, abrangendo todos os ambientes de uma área da planície litorânea do Sul do Rio Grande do Sul. Foram registrados 39 táxons específicos e infra-específicos distribuídos em 14 gêneros. Destes, os mais representativos foram Cyperus L., com 11 táxons e Eleocharis R. Br, com 10. São fornecidas chaves para identificação de gêneros e espécies e comentários sobre aspectos morfológicos, habitat, distribuiçãoe fenologia.

Palavras-chave: monocotiledôneas, vegetação litorânea de restinga, Poales, diversidade
\end{abstract}

\begin{abstract}
This work was based on analysis of herbarium materials, bibliographic documentation and collections, covering all environments from an area of the coastal plain of the southern Rio Grande do Sul. We recorded 39 specific and infra-specific taxa distributed in 14 genera. Of these, the most representative were Cyperus L. with 11 taxa and Eleocharis R. Br., with 10.Keys are provided for identification of genera and species and comments on morphological aspects, habitat, distribution and phenology.
\end{abstract}

Key words: monocots, coastal salt marsh vegetation, Poales, diversity

\section{Introdução}

Cyperaceae é cosmopolita, tem como centros de distribuição a África e os Neotrópicos (Goetghebeur 1998), abrangendo grande variedade morfológica, tendo como sinapomorfias inflorescência em espigueta e fruto do tipo aquênio.

É frequentemente lembrada por sua importância como infestante e invasora de culturas anuais (Goetghebeur 1998), porém várias espécies são utilizadas em perfumaria, artesanato, medicina tradicional, e na alimentação humana e animal (Simpson \& Inglis 2001). É também relevante em banhados e charcos, sustentando a cadeia de detritívoros (Costa et al. 2003) e constitui importante componente sucessional em áreas antropizadas (Trevisan et al. 2008).

No Brasil, são conhecidas 675 espécies distribuídas em 39 gêneros (Alves et al. 2014). Para a região sul do Brasil, a obra mais completa para a família, ainda é de Barros (1960), que inventariou
189 espécies para Santa Catarina e áreas limítrofes. Estudos posteriores envolvendo a família foram realizados, em geral em âmbito local, como Silveira \& Longhi-Wagner (2008), que citaram 40 táxons para o Morro Santana, em Porto Alegre e Viamão (RS); Trevisan et al. (2008) com 61 táxons para o Parque Estadual de Itapuã, em Viamão e Ferreira \& Eggers (2008) com 42 espécies para o Centro de Pesquisa e Conservação da Natureza Pró-Mata, em São Francisco de Paula (RS). Além destes, estudos envolvendo táxons específicos foram realizados tanto para a região Sul, como Hefler \& Longhi-Wagner (2012), que inventariam 18 táxons de Cyperus subg. Cyperus, como também para o Estado do RS, como Araújo \& Longhi-Wagner (1996), que registraram 14 táxons de Cyperus subg. Anosporum (Nees) Clarke; Trevisan et al. (2007), com 4 espécies de Kyllinga Rottb.; Trevisan \& Boldrini (2008) com 27 espécies de Eleocharis R. Br.; e Silveira \& Longhi-Wagner (2012), com

\footnotetext{
${ }^{1}$ Universidade Federal do Rio Grande, Inst. Ciências Biológicas, Av. Itália s/n, km8, Carreiros, 96203-900, Rio Grande, RS, Brasil.

${ }^{2}$ Autor para correspondência: smhefler@yahoo.com.br
} 
20 espécies de Carex L. No entanto, cabe destacar que para o extremo sul do Brasil, que engloba a planície litorânea do Rio Grande do Sul, pouco se sabe sobre a riqueza da família. As informações existentes são basicamente de listagens florísticas como Käfer et al. (2011), com 16 táxons em um banhado do Rio Grande e Jacobi et al. (2013), com 21 táxons para o Campus Carreiros, em Rio Grande. Estudos taxonômicos e florísticos na Argentina e no Uruguai também contribuem para o conhecimento da flora de Cyperaceae na região do extremo sul, como Pedersen (1969) e Marchesi \& Lombardo (1984) porém, são obras desatualizadas e que não elucidam a totalidade de espécies para esta área do Brasil.

Assim, o presente trabalho, com o objetivo de contribuir para o conhecimento da flora local de Cyperaceae, buscou inventariar as espécies em uma área da planície litorânea do extremo sul do Brasil e trazer subsídios para sua identificação.

\section{Material e Métodos}

O local de estudo (Fig. 1) possui cerca de 227 hectares e corresponde á área do Campus Carreiros, da Universidade Federal do Rio Grande - FURG, localizado no município do Rio Grande, estado do Rio Grande do Sul (Brasil) - 32 04 '18,26" S e 52 09'59,33" W (Jacobi et al. 2013).

As formações vegetacionais encontradas na área de estudo foram classificadas de acordo com Jacobi et al. (2013): áreas ajardinadas, banhados, dunas, campos antropizados, campos naturais, lagos e monocultivos de exóticas arbóreas (Fig. 2).

Para este estudo foi realizado um levantamento junto ao Herbário Universidade do Rio Grande (HURG) bem como coletas quinzenais na área de estudo, entre outubro de 2011 e novembro de 2012, por meio do método de Caminhamento (Filgueiras et al. 1994). Todo o material coletado encontra-se depositado no HURG.

Ilustração das espécies estão referidas às obras consultadas para a identificação das mesmas: Barros (1960), Guaglianone (1980), Araújo \& Longhi-Wagner (1996); Trevisan et al. (2007); Ferreira \& Eggers (2008); Silveira \& LonghiWagner (2008); Trevisan \& Boldrini (2008); Trevisan et al. (2008); Oliveira et al. (2011); Hefler \& Longhi-Wagner (2012); Silveira \& LonghiWagner (2012).

São fornecidas chaves para identificação de gêneros e espécies e comentários sobre aspectos morfológicos, habitat, distribuição e fenologia.
Para o material examinado, optou-se listar apenas uma exsicata para cada táxon estudado.

\section{Resultados e Discussão}

Foram registrados para a área de estudo 39 táxons, distribuídos em 14 gêneros, sendo 7 monoespecíficos. Os gêneros mais representativos foram Cyperus, com 11 táxons, e Eleocharis, com 10.

De acordo com a lista de espécies ocorrentes no Campus apresentada por Jacobi et al. (2013), Cyperaceae apresenta 21 espécies. Um levantamento preliminar realizado no HURG mostra a ocorrência de 18 espécies para o local. Desta forma, o presente estudo revela novas citações de ocorrência, tanto de gêneros, como Bulbostylis Steven, Carex e Fimbristylis Vahl, quanto de 17 espécies para o local.

Entre as espécies citadas por Jacobi et al. (2013), Carex bonariensis Desf. ex Poir., Cyperus alternifolius L., Cyperus eragrostis Vahl e Cyperus giganteus Vahl não foram registradas no presente estudo, tampouco constam no acervo do HURG. Entre as possibilidades para estas espécies não serem encontradas na área de estudo durante o período de coletas, pode-se atribuir as constantes modificações ocorridas no Campus em curto intervalo de tempo, em virtude de obras das novas edificações e alterações em áreas vegetadas, bem como a possíveis erros de identificação.

Rhynchospora rugosa (Vahl) Gale, citada em Jacobi et al. (2013), não foi confirmada para o local, pois a amostra utilizada trata-se de Rhynchospora barrosiana Guagl.. Oxycaryum cubense (Poepp. \& Kunth) Lye, não listada por Jacobi et al. (2013), foi registrada em levantamento das macrófitas aquáticas do Campus realizado por Trindade et al. (2010) e confirmada pelo presente estudo.

Espécies de Cyperaceae foram representativas em todos os ambientes do local de estudo, apresentando maior riqueza específica em ambientes úmidos (Fig. 3). Entre os ambientes com menor número de espécies destacam-se os monocultivos de exóticas arbóreas, onde foram encontradas apenas Androtrichum trigynum (Spreng) H. Pfeiff. Cyperus surinamensis Rottb. Eleocharis densicaespitosa R. Trevis. \& Boldrini e Rhynchospora brittonii Gale.

Cyperus rigens J. Presl. \& C. Presl. Cyperus aggregatus (Willd.) Eld., Eleocharis densicaespitosa, Kyllinga odorata Kunth e Pycreus polystachyos (Rottb.) P. Beauv. são as mais comuns da área estudada, constituindo densas populações em todos os ambientes. 


\section{Chave para gêneros de Cyperaceae em área do extremo sul do Brasil}

1. Espigueta única terminal; planta áfila.

5. Eleocharis

1'. Espiguetas reunidas em tipos variados de inflorescência; plantas providas de folhas ou áfilas.

2. Flores unissexuadas; plantas folhosas.

3. Espiguetas unifloras reunidas em espigas terminais ou dispostas ao longo do escapo; lígula adaxial presente; contralígula ausente; perigínio presente. 3. Carex

3'. Espiguetas plurifloras, reunidas em fascículos ao longo do escapo, lígula adaxial ausente, contralígula presente; perigínio ausente; aquênio livre, inserido na axila da gluma

14. Scleria distans

2'. Flores bissexuadas, plantas folhosas ou áfilas.

4. Espiguetas com glumas dísticas.

5. Estilete trífido, aquênio trígono.

6. Filamentos dos estames longos e acrescentes................ 1. Androtricum trigynum

6'. Filamentos dos estames não acrescentes.............................................. 4. Cyperus

5'. Estilete bífido, aquênio lenticular.

7. Inflorescência em espigas sésseis...................................................... 7. Kyllinga

7'. Inflorescência em antela simples, congesta ou laxa............................ 10. Pycreus

4'. Espiguetas com glumas espiraladas.

8. Estilopódio presente.

9. Estilopódio caduco.

6. Fimbristylis

9'. Estilopódio persistente

10. Estilete trífido; estilopódio bulboso.... 2. Bulbostylis communis var. scabrida

10’. Estilete bífido; estilopódio piramidal.

8'. Estilopódio ausente.

11. Plantas áfilas; inflorescência paniculóide

11. Rhynchospora

11'. Plantas folhosas; inflorescência de outros tipos.

12. Apêndices florais presentes.

12'. Apêndices florais ausentes.

13. Folhas de margens lisas, estigma bífido; aquênio lenticular; branco a palhete.

9. Oxycaryum cubense

13'. Folhas de margens escabras e cortantes; estigma trífido; aquênio trígono; palhete a cinzento. 13. Scirpus giganteus

1. Androtrichum trigynum (Spreng.) H. Pfeiff., Repert. Spec. Nov. Regni Veg. 42: 10. 1937.

Típica da região costeira do sul do Brasil (Barros 1960). Caracteriza-se pelos colmos áfilos e filamentos dos estames longos, acrescentes e hialinos, o que confere o aspecto de algodão (nome popular "algodãozinho-das-dunas"). Ocorre em campos antropizados e naturais, dunas e monocultivos de exóticas arbóreas da área estudada. Floração e frutificação de outubro a abril, com ápice nos meses de verão. (Foto: Trevisan et al. 2008). Material examinado selecionado: 20.III. 2012, fl. e fr., A.C. Soares 257 (HURG).
2. Bulbostylis communis var. scabrida M.G. López \& D.A. Simpson, Kew Bull. 67(2): 231. 2012.

Caracteriza-se pelos talos lineares com escabrosidades variáveis, folhas filiformes de margens escabrosas, inflorescência anteliforme com grande número de espiguetas, aquênios ligeiramente alargadas, com leves estriações transversais, estilopódio persistente, bulboso, de coloração castanha. (Ilustração: López \& Simpson 2012). Material examinado selecionado: 20.II. 2012, fl. e fr., A.C. Soares 136.

\section{Carex L.}

1. Espigas congestas com flores masculinas apicais 3.2. Carex.sororia

1'. Espigas espaçadas com flores masculinas basais. 3.1 Carex. longii subsp. meridionalis

\footnotetext{
* para gêneros representados por uma única espécie, a espécie é apresentada diretamente na chave.
} 
3.1 Carex longii Mack. subsp. meridionalis (Kük.) G.A.Wheeler, Aliso 11(4): 536. 1987.

Caracteriza-se pela inflorescência em espigas espaçadas com flores masculinas basais. Ocorre em banhados e campos naturais da área estudada. Floresce na primavera e frutifica no verão e outono. (Ilustração: Silveira \& LonghiWagner 2012).

Material examinado selecionado: 04.XI.2011, fl., A.C. Soares 20 (HURG).
3.2 Carex sororia Kunth, Enum Pl., 2: 379. 1837.

Caracteriza-se pela inflorescência em espigas congestas apicais e pela presença de flores masculinas apicais. Ocorre em áreas ajardinadas e campos antropizados. Floração e frutificação no verão e outono. (Ilustração Silveira \& Longhi-Wagner 2012). Material examinado selecionado: 18.XI.2011, fl., A.C. Soares 48 (HURG).

\section{Cyperus L.}

1. Plantas áfilas, inflorescência sub-terminal

4.3. Cyperus haspan var. haspan

1'. Plantas folhosas, inflorescência terminal.

2. Inflorescência em antelódio simples ou composto com espiguetas agrupadas em espigas verdadeiras no ápice dos ramos, formando umbelas congestas ou ainda espigas subsésseis terminais.

3. Espigas laxas, patentes.

4. Plantas rizomatosas, espiguetas com ráquila articulada entre as glumas férteis, desprendendo-se em fragmentos uninucígeros. ..4.5. Cyperus odoratus

4'. Plantas com rizomas estoloníferos; espiguetas com ráquila não articulada entre as glumas férteis.

5. Lígula adaxial presente; glumas múticas, vináceas; aquênios castanhos a vináceos. 4.10. Cyperus rotundus

5'. Lígula adaxial ausente; glumas mucronadas, amareladas; aquênios palhetes a acinzentados.

4.2. Cyperus esculentus

3'. Espigas densas, congestas.

6. Espigas subsésseis terminais; glumas verdes a estramíneas.

4.1. Cyperus aggregatus

6'. Espigas pedunculadas, situadas no ápice dos ramos de antelódio simples ou composto, glumas palhetes ou vináceas.

7. Inflorescência em antelódio simples contraído de ramos não pendentes; espigas obovoides a globosas; espiguetas patentes. 4.9. Cyperus rigens

7'. Inflorescência em antelódio simples ou composto de ramos longos e pendentes; espigas cilíndricas; espiguetas eretas. 4.6. Cyperus prolixus

2'. Inflorescência monocéfala ou em antelódio simples ou composto com espiguetas reunidas em inflorescência digitada, capituliforme, nunca espigas verdadeiras.

8. Inflorescência monocéfala 4.8. Cyperus reflexus var. reflexus

8'. Inflorescência em antela simples ou composta.

9. Inflorescência em antela simples, contraída, glumas vináceas

4.7. Cyperus reflexus var. fraternus

9'. Inflorescência em antela simples ou composta, glumas esverdeadas a palhetes.

10. Escapos e folhas de margens escabrosas; antela composta, raios de superfície espinulosa; espiguetas lanceolado-ovais, 14-18 flores; aquênios levemente estipitados, castanhos, superfície zonado-rugosa, ápice não comprimido......

4.11. Cyperus surinamensis

10'. Escapos e folhas de margens lisas; antela simples, raios de superfície lisa; espiguetas obovoide-oblongas, 18-25 flores; aquênios não estipitados, negros, superfície lisa, ápice gradualmente comprimido.

4.4. Cyperus luzulae var. entrerianus 

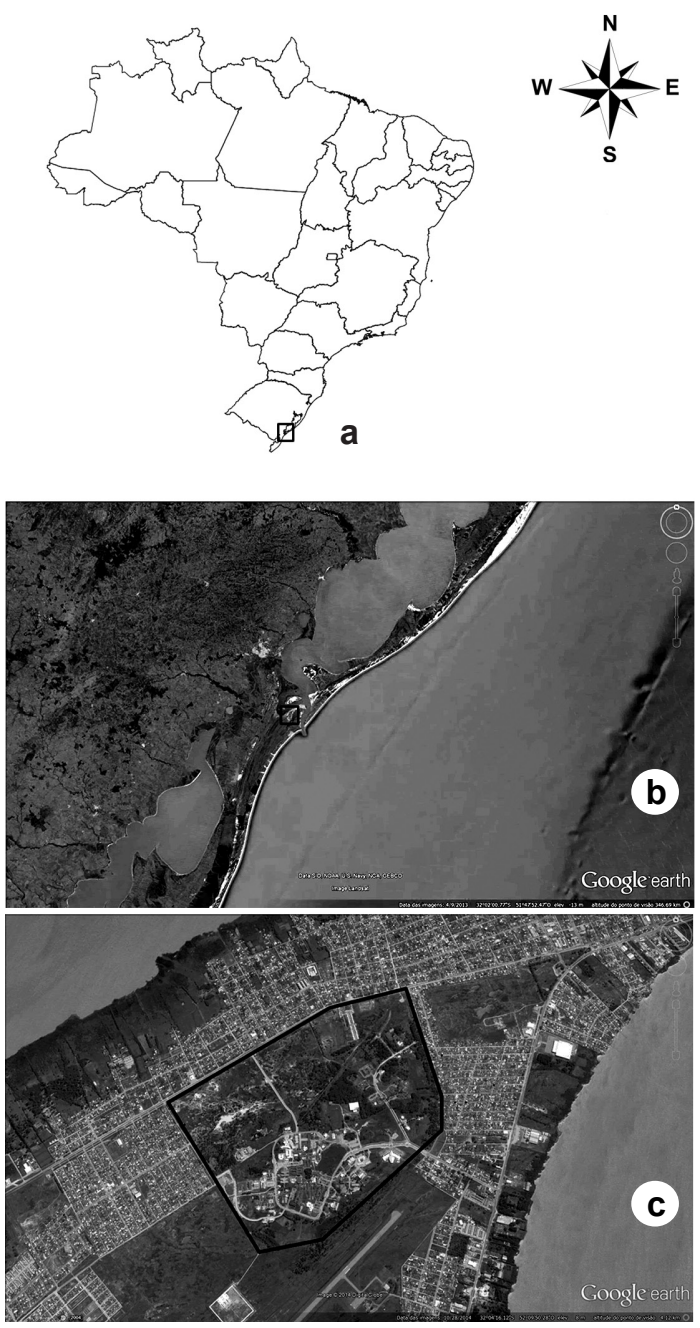

Figura 1 - Área de estudo: a. localização do município do Rio Grande, Rio Grande do Sul, Brasil (fonte: IBGE 2014); b. indicação do Campus Carreiros, FURG, Rio Grande (quadrado); c. pormenor da área de estudo. (b-c. fonte: Google Earth 2014)

Figure 1 - Study área: a. county of Rio Grande, Rio Grande do Sul, (from IBGE, 2014); b. location of the Campus Carreiros, FURG, Rio Grande (square); c. detail of the study area (b-c from Google Earth 2014).

4.1 Cyperus aggregatus (Willd.) Endl., Cat. Horti Vindob. 1: 93. 1842.

Caracteriza-se pela inflorescência composta de várias espigas cilíndricas subsésseis, de coloração esverdeada, inseridas no ápice dos ramos floríferos. Ocorre em áreas ajardinadas, campos naturais, campos antropizados, dunas e monocultivos de exóticas arbóreas. Floração e frutificação de setembro a maio. (Ilustração: Hefler \& Longhi-Wagner 2012).
Material examinado selecionado: 16.II.2012, fl. e fr., A.C. Soares 145 (HURG).

\subsection{Cyperus esculentus L., Sp. Pl. 1: 45. 1753.}

Caracteriza-se pelas espiguetas laxas, patentes e de glumas amareladas, facilmente reconhecíveis a campo. Ocorre em áreas ajardinadas e campos antropizados. Floração e frutificação de outubro a abril. (Ilustração: Hefler \& Longhi-Wagner 2012). Material examinado selecionado: 20.IV.2012, fl. e fr. A.C. Soares 272 (HURG).

\subsection{Cyperus haspan L., Sp. Pl. 45. 1753.}

Caracteriza-se pelas folhas reduzidas a bainhas e inflorescência subterminal. Ocorre em lagos e banhados da área estudada. Floração e frutificação de setembro a abril, com ápice de novembro a fevereiro. (Ilustração: Araújo \& Longhi-Wagner 1996).

Material examinado selecionado: 20 III. 2012, fl. e fr, A.C. Soares 261 (HURG).

4.4 Cyperus luzulae var. entrerianus (Boeck.) Barros, Anales Mus. Nac. Hist. Nat. Buenos Aires 39: 309. 1938.

Caracteriza-se pelos talos lisos, folhas lustrosas sem escabrosidades, espiguetas ovais, com 18 a 25 flores, glumas não mucronadas; aquênio castanho escuro a negro, gradualmente atenuado de baixo para cima. Ocorre em banhados e campos naturais da área estudada. Floração e frutificação de novembro a abril. (Ilustração: Araújo \& Longhi-Wagner 1996).

Material examinado selecionado: 25.I.2012, fl. e fr., A.C. Soares 94 (HURG).

\subsection{Cyperus odoratus L., Sp. Pl. 1: 46. 1753.}

Caracteriza-se pela ráquila articulada entre as glumas férteis, desprendendo-se em fragmentos uninucígeros, o que a distingue de todas as outras espécies do gênero na área. Ocorre em banhados e lagos da área estudada. Floração e frutificação de outubro a maio. (Ilustração: Hefler \& LonghiWagner 2012).

Material examinado selecionado: 20.III. 2012, fl. e fr, A.C. Soares 253 (HURG).

4.6 Cyperus prolixus Kunth, Nov. Gen. Sp. 1: 206. 1815(1816).

Caracteriza-se pela inflorescência em antelódio composto com ramos longos e pendentes na maturidade, e espiguetas ascendentes agrupadas em densas espigas e glumas castanhas a levemente avermelhadas. 

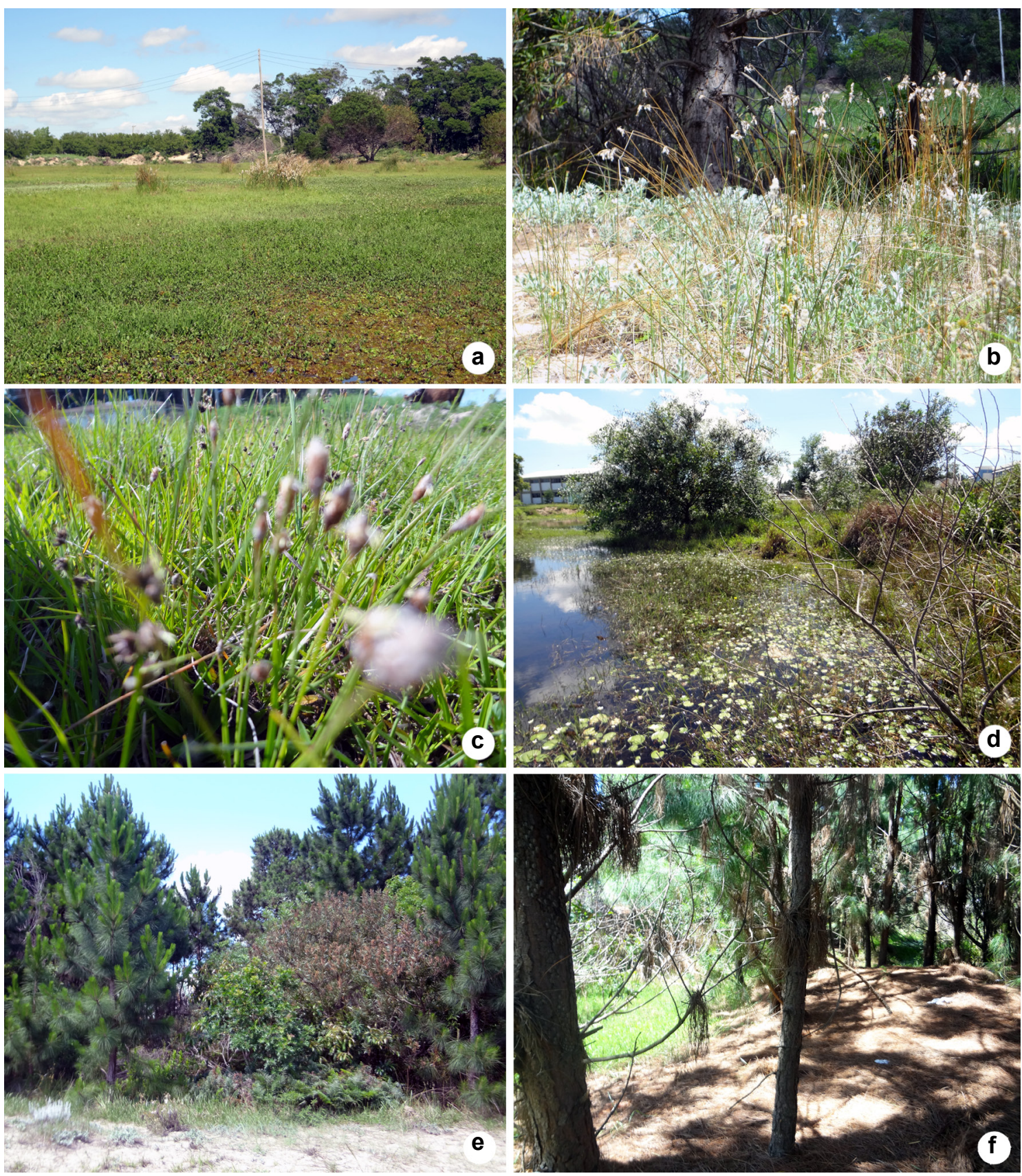

Figura 2 - Ambientes do Campus Carreiros, FURG, Rio Grande - a. banhado; b. dunas; c. campo natural; d. lago; e. monocultivo de exóticas arbóreas; f. monocultivo de exóticas arbóreas - interior da área

Figure 2 - Campus Carreiros environments, FURG, Rio Grande - a. plated; b. dunes; c. natural field; d. lake; e.monoculture tree exotic; f. monoculture tree exotic - Inside Area.

Ocorre em banhados, campos naturais e lagos. Floração e frutificação de outubro a março. (Ilustração: Hefler \& Longhi-Wagner 2012).

Material examinado selecionado: 25.I.2012, fl. e fr., A.C. Soares 110 (HURG).
4.7 Cyperus reflexus var. fraternus (Kunth) Kuntze, Revis. Gen. Pl. 3(3): 334. 1898.

Caracteriza-se pela inflorescência em glomérulo, espiguetas lanceolado-oblongas, glumas violáceas e aquênios elipsoides. Ocorre em banhados 
e campos naturais. Floração e frutificação de setembro a abril. (Ilustração: Araújo \& Longhi-Wagner 1996). Material examinado selecionado: 20.X.2011, fl., A.C. Soares 05 (HURG).

4.8 Cyperus reflexus var. reflexus Boeck. Linnaea 35: 558. 1867.

Caracteriza-se pela inflorescência monocéfala, espiguetas oblongas a orbiculares, glumas violáceas e aquênios ligeiramente globosos. Ocorre em campos antropizados e naturais. Floração e frutificação de setembro a março. (Ilustração: Araújo \& Longhi-Wagner 1996). Material examinado selecionado: 20.X.2011, fl., A.C. Soares 06 (HURG).

4.9 Cyperus rigens J. Presl \& C. Presl, Reliq. Haenk. 1(3): 170. 1828.

Caracteriza-se pela inflorescência em espigas densas ou subdensas de formato ovóide a globoso, inseridas no ápice de antelódio simples contraído, terminal, com glumas castanho-amareladas a castanho-escuras. Ocorre em banhados, campos antropizados e lagos. Floresce e frutifica de setembro a abril. (Ilustração: Hefler \& Longhi-Wagner 2012). Material examinado selecionado: 16.II.2012, fl. e fr., A.C. Soares 127 (HURG).
4.10 Cyperus rotundus L., Sp. Pl. 1: 45. 1753.

Caracteriza-se por rizomas estoloníferos, lígula adaxial e espiguetas linear-lanceoladas com glumas fortemente vináceas. Ocorre em áreas ajardinadas e campos antropizados. Floração e frutificação de outubro a maio. (Ilustração: Hefler \& Longhi-Wagner 2012).

Material examinado selecionado: 25.I. 2012, fl. e fr., A.C. Soares 59 (HURG).

4.11 Cyperus surinamensis Rottb., Descr. Icon. P1. Rar.: 35. 1773.

Caracteriza-se pela presença de escabrosidades na face de escapos e margens das folhas, conferindo textura áspera ao toque; pelas glumas mucronadas e aquênio castanho a ferruginoso, nunca negro. Ocorre em áreas ajardinadas, banhados, campos antropizados, lagos e monocultivos de exóticas arbóreas. Floração de setembro a janeiro; frutificação de dezembro a junho. (Ilustração: Araújo \& LonghiWagner 1996).

Material examinado examinado: 20 X.2011, fl., A.C. Soares 14 (HURG).

\section{Eleocharis R. Br.}

1. Escapos ocos septados.

5.7. Eleocharis montana

1'. Escapos esponjosos não septados.

2. Gluma inferior fértil.

5.1. Eleocharis bonariensis

2'. Gluma inferior estéril.

3. Bainha com apêndice hialino rugoso no ápice.

4. Espiguetas vináceas; aquênios negros, obovóides, com cerdas hipóginas tão longas quanto o aquênio. 5.2. Eleocharis maculosa

4'. Espiguetas palhetes a castanhas; aquênios oliváceos a castanhos, obovóides ou lenticulares, com cerdas hipóginas mais curtas que o aquênio.

5. Gluma inferior com margem hialina ampla; estilete trífido; aquênios obovóides, castanhos. 5.3. Eleocharis flavescens

5'. Gluma inferior com margem hialina estreita; estilete bífido; aquênios obovóides ou lenticulares, oliváceos a negros. 5.8. Eleocharis sellowiana

3’. Bainha sem apêndice hialino no ápice.

6. Glumas superiores com ápice emarginado; aquênios palhetes, cerdas hipóginas ausentes. 5.2. Eleocharis densicaespitosa

6'. Glumas superiores com ápice acuminado, agudo ou obtuso; aquênios oliváceos a negros; cerdas hipóginas presentes.

7. Estilete bífido; aquênio biconvexo. 5.4. Eleocharis geniculata

7'. Estilete trífido; aquênio trígono.

8. Escapos cilíndricos; espigueta nunca prolífera; gluma inferior com margem hialina estreita 5.9. Eleocharis subarticulata

8'. Escapos quadrangulares; espiguetas prolíferas ou não prolíferas; gluma inferior com margem hialina ampla. 
9. Colmos capilares; gluma inferior membranácea, mais curta que as superiores adjacentes

5.6. Eleocharis minima

9'. Colmos não capilares; gluma inferior cartilaginosa, subigual ou ultrapassando as restantes.

5.10. Eleocharis viridans

5.1 Eleocharis bonariensis Nees in Hook., J. Bot. 2: 398.1840.

Caracteriza-se pela gluma inferior fértil. Ocorre em banhados. Floração e frutificação nos meses de verão e outono. (Ilustração: Silveira \& Longhi-Wagner 2008).

Material examinado: 25.I.2012, fl. e fr., A.C. Soares 68 (HURG).

5.2 Eleocharis densicaespitosa R. Trevis. \& Boldrini, Syst. Bot. 35: 505. 2010.

Endêmica da planície costeira do Rio Grande do Sul (Trevisan \& Boldrini 2008) caracteriza-se pelos escapos não septados, rizomas sublenhosos, espiguetas palhetes, com glumas de ápice emarginado, sendo a inferior estéril, cartilaginosa, ultrapassando, em comprimento, as demais, pelo aquênio trígono, palhete, e pela ausência de cerdas hipóginas. Ocorre em áreas ajardinadas, banhados, campos antropizados e naturais, dunas, lagos e monocultivos de exóticas arbóreas. Floração e frutificação de setembro a maio, com ápice de novembro a março. (Ilustração: Trevisan \& Boldrini 2008).

Material examinado selecionado: 18. X. 2011, fl., A.C. Soares 38 (HURG).

5.3 Eleocharis flavescens (Poir.) Urb., Symb. Antill. 4(1): 116. 190.

Caracteriza-se pelo ápice da bainha hialiano, longo e envolvendo inicialmente o escapo, espiguetas palhetes a castanho-claras e pelo aquênio castanho com cerdas hipóginas mais curtas que o comprimento do fruto. Ocorre em banhados. Floração e frutificação de setembro a abril. (Ilustração: Trevisan \& Boldrini 2008).

Material examinado selecionado: VIII.2012, fr., J.L.Villar 57 (HURG).

5.4 Eleocharis geniculata (L.) Roem. \& Schult., Syst. Veg. 2: 150. 1817.

Caracteriza-se pelas espiguetas arredondadas a globosas, brilhantes, de coloração vinácea e pelos aquênios negros, lisos, brilhantes, biconvexos, com grande variação morfológica quanto à presença de cerdas hipóginas. Ocorre em campos antropizados e banhados. Floração e frutificação de setembro a abril. (Ilustração: Trevisan \& Boldrini 2008).

Material examinado selecionado: $16 . I I I .2012$, fl. e fr., A.C. Soares 243 (HURG).

5.5 Eleocharis maculosa (Vahl) Roem. \& Schult., Syst. Veg. 2: 154. 1817.

Caracteriza-se pelas espiguetas vináceas e aquênio castanho escuro a negro, com cerdas hipóginas longas. Ocorre em banhados e lagos. Floração e frutificação de setembro a junho. (Ilustração: Trevisan \& Boldrini 2008).

Material examinado selecionado: 20 IV.2012, fl. e fr., A.C. Soares 284 (HURG).

5.6 Eleocharis minima Kunth, Enum. Pl. 2: 139. 1837.

Caracteriza-se pelos escapos capilares, quandrangulares com até $6,5 \mathrm{~cm}$ alt., com cáudice, espiguetas com 4-8 flores, glumas superiores membranáceas e aquênios oliváceos a esbranquiçados e estilopódio oliváceo. Ocorre em banhados, campos antropizados e naturais e lagos. Floração e frutificação de setembro a maio. (Ilustração: Trevisan \& Boldrini 2008).

Material examinado selecionado: 13.XII.2000, fl., S.C. (HURG 2843).

5.7 Eleocharis montana (Kunth) Roem. \& Schult., Syst. Veg. 2: 153. 1817.

Caracteriza-se pelos escapos septados e espiguetas palhetes e comprimidas lateralmente, especialmente na parte superior. Ocorre em banhados e lagos Floração e frutificação nos meses de primavera a outono. (Ilustração: Trevisan \& Boldrini 2008).

Material examinado selecionado: 19.XII. 2012, fl. e fr., U.S. Jacobi 4840 (HURG).

5.8 Eleocharis sellowiana Kunth, Enum. Pl. 2: 149. 1837.

Caracteriza-se pela bainha com apêndice rugoso hialino no ápice, espiguetas palhetes a castanhas, aquênios lenticulares e oliváceos. Ocorre em banhados, campos naturais e lagos. Floração e frutificação de setembro a maio. (Ilustração: Trevisan \& Boldrini 2008). 
Material examinado selecionado: 04.XII.2011, fl. e fr., A.C. Soares 21 (HURG).

5.9 Eleocharis subarticulata (Nees) Boeck., Linnaea 36: 455. (1869-70).

Possui rizomas de entrenós curtos, espiguetas lanceoladas, glumas superiores de ápice agudo e aquênios oliváceos a castanhos, levemente reticulados. Ocorre em banhados e campos naturais. Floração e frutificação de setembro a maio. (Ilustração: Trevisan \& Boldrini 2008).

Material examinado selecionado: 6.X.2011, fl. e fr., J.L. Villar 75 (HURG).
5. 10 Eleocharis viridans Kük. ex Osten, Anales Mus. Hist.Nat. Montevideo, ser. 2, 3: 175. 1931.

Caracteriza-se pelos escapos quadrangulares, espiguetas cilíndricas, glumas superiores espiraladas, gluma inferior subigual ou ultrapassando as adjacentes. Ocorre em banhados, campos antropizados e naturais. Floração e frutificação de outubro a abril. (Ilustração: Trevisan \& Boldrini 2008).

Material examinado selecionado: 04.XI. 2011, fl. e fr., A.C. Soares 25 (HURG).

\section{Fimbristylis Vahl}

1. Espiguetas linear-lanceoladas; estilete trífido; estigma não fimbriado; aquênio grisáceo, liso ou com leves estriações transversais, trígono. 6.1. Fimbristylis autumnalis

1'. Espiguetas lanceolado-oblongas; estilete bífido; estigma fimbriado; aquênio castanho-avermelhado a castanho escuro, reticulado, cordiforme, biconvexo. 6.2. Fimbristylis dichotoma

6.1 Fimbristylis autumnalis (L.) Roem. \& Schult., Syst.Veg. 2: 97. 1817.

Caracteriza-se pela inflorescência em antelódio composto, espiguetas linear-lanceoladas e de coloração castanho-escura, estigma trífido e aquênio trígono, liso ou com leves pontuações transversais, de coloração variável entre grisáceo e castanho. Ocorre em áreas ajardinadas, banhados, campos naturais e antropizados, dunas e lagos. Floração e frutificação nos meses de outubro a abril. (Foto: Trevisan et al. 2008).

Material examinado selecionado: 20.III.2012, fr., A.C. Soares 283 (HURG).
6.2 Fimbristylis dichotoma (L.) Vahl, Enum. Pl. 2: 287.1805.

Caracteriza-se pelas espiguetas lanceoladoovóides, castanho-claras; estigma bífido; e aquênio biconvexo, de formato obovóide a cordiforme, coloração castanho-avermelhado a castanho-escuro, com cristas longitudinais conferindo-lhe aspecto vítreo. Ocorre em áreas ajardinadas, banhados, campos naturais, campos antropizados, dunas e lagos. Floração e frutificação de setembro a maio. (Ilustração: Silveira \& Longhi-Wagner 2008).

Material examinado selecionado: 09.IV.2012, fr., A.C. Soares 267 (HURG).

\section{Kyllinga Rottb.}

1. Plantas cespitosas, às vezes com rizomas de entrenós curtos; espigas $1-4$, sendo a central maior do que as demais; presença eventual de espiguetas bifloras, neste caso a superior é estaminada

7.1. Kyllinga odorata

1’. Plantas rizomatosas; espigas monocéfalas; espiguetas exclusivamente unifloras.

7.2. Kyllinga vaginata

7.1 Kyllinga odorata Vahl, Enum. Pl. 2: 382. 1805.

Caracteriza-se pelo hábito cespitoso, inflorescência estramínea, capitada, com 1-4 espigas, sendo a central maior que as outras. Ocorre em áreas ajardinadas, campos naturais e antropizados, dunas e monocultivo de exóticas arbóreas. Floração e frutificação durante o ano todo. (Ilustração: Trevisan et al. 2007). Material examinado selecionado: 19.XI.2012, fl. e fr., A.C. Soares 318 (HURG). 
7.2 Kyllinga vaginata Lam., Encycl. 1: 148. 1791.

Caracteriza-se pelos rizomas engrossados e levemente vináceos ou castanho-claros e delgados; inflorescência com 1-2 espigas e espiguetas exclusivamente unifloras. Ocorre em áreas ajardinadas, banhados, campos antropizados, campos naturais, dunas e lagos. Floração e frutificação de outubro a junho. (Ilustração: Trevisan et al. 2007). Material examinado selecionado: 20.XI.2012, fl. e fr., A.C. Soares 313 (HURG).

8. Licocarpha humboldtiana Nees, Linnaea 9: 287.1834.

Caracteriza-se pela inflorescência em 3-6 espigas apicais sésseis, ovóides e espiguetas unifloras. Ocorre em áreas ajardinadas, banhados e campos antropizados e naturais. Foi encontrada uma população bem estabelecida em uma área de dunas. Floração e frutificação de novembro a maio. (Foto: Trevisan et al. 2008).

Material examinado selecionado: 25.I.2012, fl e fr, A.C. Soares 66 (HURG).

9. Oxycaryum cubense (Poepp. \& Kunth) Lye, Bot. Nat. 124: 281. 1971.

Caracteriza-se pela inflorescência em antela simples, contraída e por ocorrer como epífita em plantas de Salvinia sp. e Typha sp. dos banhados e lagos do local de estudo, enraizando-se posteriormente. (Foto: Trindade et al. 2010).

Material examinado selecionado: 11 XII 2014, fl. e fr., A.C. Soares 334 (HURG).

10. Pycreus P. Beauv.

1. Inflorescência em antela simples, contraída, ou congesta; glumas lateralmente vináceas.

1'. Inflorescência em antela simples laxa; glumas esverdeadas a palhetes. 10.2 Pycreus polystachyos 10.1. Pycreus lanceolatus

10.1 Pycreus lanceolatus (Poir.) C.B. Clarke, Consp. Fl. Afr. 5: 538. 1894.

Caracteriza-se pela inflorescência laxa, em antelódio simples; espiguetas palhetes pediceladas, aquênio orbicular em vista lateral. Ocorre em banhados, campos naturais e lagos. Floração e frutificação de outubro a abril. (Ilustração: Silveira \& Longhi-Wagner 2008).

Material examinado selecionado: 20.IV.2012, fl. e fr., A.C. Soares 277 (HURG).
10.2 Pycreus polystachyos (Rottb.) P. Beauv., Fl. Oware, 2: 48. 1807.

Caracteriza-se pela inflorescência contraída, capituliforme, glumas lateralmente vináceas e aquênios oblongos em sua vista lateral. Ocorre em áreas ajardinadas, campos antropizados e naturais, dunas, lagos e monocultivo de exóticas arbóreas. Floração e frutificação de outubro a maio. (Ilustração: Silveira \& Longhi-Wagner 2008).

Material examinado selecionado: 16.III.2012, fl. e fr., A.C. Soares 239 (HURG).

\section{Rhynchospora Vahl}

1. Inflorescência anteliforme, com espiguetas lanceoladas agrupadas em fascículos no ápice dos ramos; cerdas hipóginas ausentes. 11.3. Rhynchospora tenuis

1'. Inflorescência fasciculada ou glomeruliforme; cerdas hipóginas presentes.

2. Inflorescências fasciculadas; espiguetas lanceolado-oblongas, ferrugíneas; aquênio lenticular, castanho escuro, com 9 a 12 rugas transversais conspícuas, com 5 a 6 cerdas hipóginas ultrapassando o aquênio; estilopódio sem dentes laterais, sulco entre sua base e o corpo do aquênio.

11.1. Rhynchospora barrosiana

2'. Inflorescências glomeruliformes; espiguetas globosas, às vezes geminadas, castanho escuras; aquênio obovóide a globoso, rugosidades transversais variáveis, 5 ou 6 cerdas hipóginas de mesmo tamanho do aquênio; estilopódio sem dentes laterais e sulcos. 


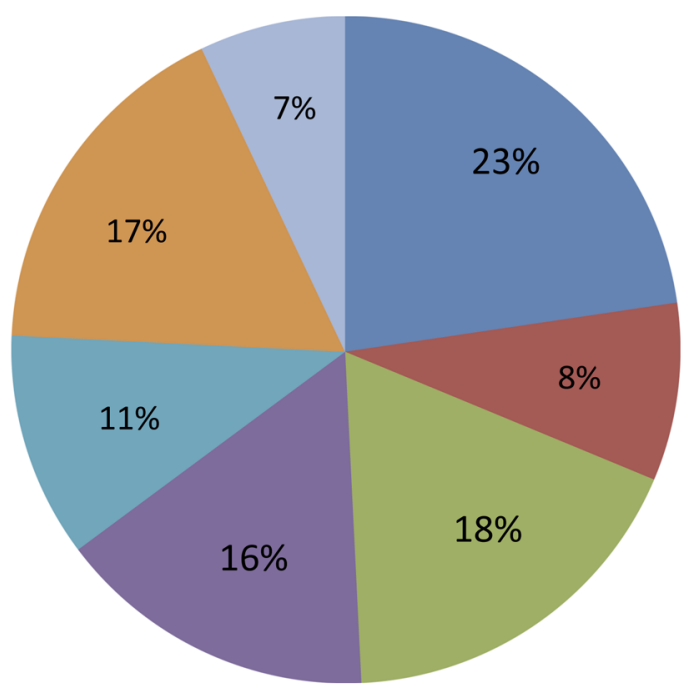

1 Banhados

2 Dunas

3 Campos naturais

- 4 Campos antropizados

5 Áreas ajardinadas

6 Lagos

7 Monocultivo de exóticas arbóreas

Figura 3 - Ocorrência de espécies de Cyperaceae nos ambientes do Campus Carreiros, FURG, Rio Grande. Figure 3 - Occurrence of species of Cyperaceae on habitats found in the Campus Carreiro, FURG, Rio Grande.

11.1 Rhynchospora barrosiana Guagl., Darwiniana 22(3-4): 287. 1979.

Caracteriza-se pela inflorescência em fascículos densos, espiguetas lanceolado-ovóides ferrugíneas, aquênio amarelado a amarronzado, com 9-12 rugosidades, sulcos transversais bem marcados e rostro triangular ou liguliforme, confluente, com sulco central bem marcado e 6 cerdas hipóginas. Ocorre em banhados e campos naturais. Floração e frutificação de outubro a março. (Ilustração: Silveira \& Longhi-Wagner 2008).

Material examinado selecionado: 18.XII.2011, fl. e fr., A.C. Soares 24 (HURG).

11.2 Rhynchospora brittonii Gale, Rhodora, 46: 241. 1944.

Caracteriza-se pela inflorescência glomeruliforme, espiguetas globoso-ovaladas, às vezes ocorrendo geminadas, com 3-4 flores; glumas castanho-escuras; aquênio obovóide a globoso, com rugas transversais e 5 a 6 cerdas hipóginas do mesmo tamanho do aquênio. Ocorre em dunas, lagos e monocultivo de exóticas arbóreas. Floração e frutificação de setembro a março. (Foto: Trevisan et al. 2008).

Material examinado selecionado: 16.III.2012, fr., A.C. Soares 240 (HURG).

11.3 Rhynchospora tenuis Link, Jahrb. Gewächsk. 1(3): 76.1820.

Caracteriza-se pela inflorescência anteliforme, pauciflora, laxa; espiguetas castanhas a ferruginosas, 2-5 em fascículos no ápice dos ramos; aquênio estramíneo a castanho, com rugosidades transversais, cerdas hipóginas ausentes e estilopódio estreito e bilobado. Ocorre em áreas ajardinadas, banhados, campos naturais e antropizados, dunas e lagos. Floração e frutificação de outubro a maio. (Ilustração: Silveira \& LonghiWagner 2008).

Material examinado examinado: $10 . I V .2012$, fl. e fr., A.C. Soares 231 (HURG).

12. Schoenoplectus californicus (C.A. Mey.) Soják, Cas. Nar. Mus., Odd. Prir. 140 (3-4): 127. 1972.

Caracteriza-se pelos colmos de cerca de $2 \mathrm{~m}$ alt., áfilos, lineares e inflorescência paniculóide longa e pendente, com glumas avermelhadas. Ocorre em banhados e lagos. Floresce e frutifica de outubro a maio. (Foto: Trevisan et al. 2008).

Material examinado selecionado: 19.XI.2012, fr., A.C. Soares 300 (HURG).

13. Scirpus giganteus Kunth, Enum. Pl. 2: 172. 1837.

Caracteriza-se pelo grande porte (até $2 \mathrm{~m}$ alt.) e folhas com margens e quilha escabrosas, cortantes; inflorescência parcial antelóide com ramos longos e pendentes e glomérulos reunindo espiguetas numerosas de glumas ferrugíneas a castanhas e filamentos dos estames longos e acrescentes, conferindo aspecto plumoso. Ocorre em banhados e lagos da área estudada. Floresce e frutifica de setembro a abril. (Foto: Trevisan et al. 2008).

Material examinado selecionado: 19.XI.2012, fl. e fr, A.C. Soares 302 (HURG).

14. Scleria distans Poir., Enclyc. 7:4. 1806

Caracteriza-se pelas inflorescências em fascículos ao longo do escapo e aquênio obovóide 
a globoso, grisáceo ou branco, posicionado livre na axila da gluma. Ocorre em banhados, campos naturais e lagos. Floresce e frutifica de setembro a abril. (Ilustração: Silveira \& Longhi-Wagner 2008). Material examinado selecionado: 19.XI.2012, fl. e fr, A.C. Soares 298 (HURG).

\section{Agradecimentos}

Aos técnicos do Laboratório de Botânica do Instituto de Ciências Biológicas da Universidade Federal do Rio Grande, o auxilio. À vigilância do Campus Carreiros, o apoio logístico e proteção durante as expedições de coleta. À FAPERGS, a bolsa concedida à primeira autora. Aos colegas $\mathrm{e}$ professores da FURG, o auxilio e informações.

\section{Referências}

Alves, M.; Hefler, S.; Trevisan, R.; Silva Filho, P. \& Ribeiro, A. 2014. Cyperaceae In: Lista de Espécies da Flora do Brasil. Jardim Botânico do Rio de Janeiro. Disponível em <http://floradobrasil.jbrj.gov.br/jabot/ floradobrasil/FB100>. Acesso em 15 setembro 2014.

Araújo, A. \& Longhi-Wagner, H. 1996. Levantamento taxonômico de Cyperus L. subg. Anosporum (Nees) Clarke (Cyperaceae-Cyperae) no RS, Brasil. Acta Botânica Brasilica 10: 153-192.

Barros, M. 1960. Las Ciperaceas del Estado de Santa Catalina. Sellowia 12: 181-450.

Costa, C.; Irgang, B.; Peixoto, A. \& Marangoni, J. 2003. Composição florística das formações vegetais sobre uma turfeira topotrófica da planície costeira do Rio Grande do Sul, Brasil. Acta Botânica Brasílica 17: 203-212.

Ferreira, P. \& Eggers, L. 2008. Espécies de Cyperaceae do Centro de Pesquisa e Conservação da Natureza Pró-Mata, município de São Francisco de Paula, Rio Grande do Sul, Brasil. Acta Botânica Brasilica 22: 173-185.

Filgueiras, T.; Nogueira, P.; Brochado, A. \& Gualaii, G. 1994. Caminhamento - um método expedito para levantamentos florísticos qualitativos. Cadernos de Geociências 12: 39-43.

Goetghebeur, P. 1998. Cyperaceae. In: Kubitzki, K.; Huber, H.; Rudall, P.; Stevens, P. \& Stützel, T. The Families and Genera of Vascular Plants IV: Flowering plants - monocotyledons. Springer-Verlag, Berlin. Pp. 141-190.

Google Earth 2014. Disponível em < http://www.earth. google.com/> Acesso em 20 dezembro 2014.

Guaglianone, E. 1980. Contribución al estúdio del gênero Rhynchospora Vahl (Cyperaceae) II. Darwiniana, 22: 499-509
Hefler, S. \& Longhi-Wagner, H. 2012. Cyperus L. subg. Cyperus (Cyperaceae) na região Sul do Brasil. Revista Brasileira de Biociências 10: 327-372.

IBGE. 2014. Instituto Brasileiro de Geografia e Estatística. Disponível em $<$ http://www.earth. google.com/www.ibge.gov/br/>. Acesso em 20 dezembro 2014.

Jacobi, U.; Duarte, C.; Gonçalves, R.; Acunha, J. \& Hefler, S. 2013. Florística dos ecossistemas do Campus Carreiros, Rio Grande, Rio Grande do Sul, Brasil. Iheringia, Série Botânica 68: 73-89.

Käfer, D.; Colares, I. \& Hefler, S.M. 2011. Composição florística e fitossociologia de macrófitas aquáticas em um banhado continental em Rio Grande, RS, Brasil, Rodriguesia 62: 835-846.

López M. \& Simpson, D. 2012. The Bulbostylis capillaris complex in southern South America. Kew Bulletin 67: 225-234.

Marchesi, E. \& Lombardo, A. 1984. Flora Montevidensis. Intendencia Municipal de Montevideo 3: 279-342.

Oliveira, A.; Gil, A. \& Bove, C. 2011. Hydrophitic Cyperaceae from the Araguaia river basin, Brazil. Rodriguesia 62: 847-866.

Pedersen, I. 1969. Flora de la Provincia de Buenos Aires. Coleção Científica do Instituto Nacional de Tecnologia Agropecuária 4: 315-421.

Silveira, G. \& Longhi-Wagner, H. 2008. Cyperaceae Juss. no Morro Santana - Porto Alegre e Viamão, Rio Grande do Sul, Brasil. Iheringia, Série Botânica 63: 295-320.

Silveira, G. \& Longhi-Wagner, H. 2012. O gênero Carex L. (Cyperaceae) no Rio Grande do Sul, Brasil. Revista Brasileira de Biociências 10: 373-417.

Simpson, D. \& Inglis, C. 2001. Cyperaceae of economic, ethnobotanical and horticultural importance: a checklist. Kew Bulletin 56: 257-360.

Trevisan, R.; Lüdtke, R. \& Boldrini, I. 2007. O gênero Kyllinga Rottb. (Cyperaceae) no Rio Grande do Sul, Brasil. Revista Brasileira de Biociências 5: 27-36.

Trevisan, R \& Boldrini, I. 2008. O gênero Eleocharis R. Br. (Cyperaceae) no Rio Grande do Sul, Brasil. Revista Brasileira de Biociências 6: 7-67.

Trevisan, R.; Ferreira, P. \& Boldrini, I. 2008. A família Cyperaceae no Parque Estadual de Itapuã, Viamão, Rio Grande do Sul, Brasil. Revista Brasileira de Biociências 6: 217-244.

Trindade, C.; Pereira, S.; Albertoni, E. \& PalmaSilva, C. 2010. Caracterização e Importância das Macrófitas Aquáticas com ênfase nos Ambientes Límnicos do Campus Carreiros, FURG, Rio Grande, RS. Cadernos de Ecologia Aquática 5: $1-22$. 


\section{Lista de Exsicatas:}

Bonilha, C. 4791 (2); Collares, I. 1926 (4.5), 1057 (6.1); Duarte, C. 4665 (5.8); Garcia, E. 4147 (4.3), 4138 (5.10); Hefler, S. 336 (4.5); Irgang, B. 1206 (14); Jacobi, U.4840 (5.7), 4838 (11.3); Neves, L. 1526, 10733 (3.2), 1508, 1932, 1944, 1968 (4.4), 1503,1777 (4.6), 1506, 1507, 1601 (4.7), 2177, 10104, 11337 (13); Soares, A. 35, 37, 74, 96, 124, 134, 223, 257 (1), 114, 130, 136, 186, 196, 200, 210, 213, 222, 242, 248, 249, 281, 290 (2), 20,31 (3.1), 48, 57 (3.2), 67, 145, 234, 252, 333 (4.1) 268, 272 (4.2), 23, 104, 137, 143, 250, 261, 282, 304, 321 (4.3), 94, 135, 224 (4.4), 253, 255, 280 (4.5), 22, 32, 56, 93, 95, 110, 262 (4.6), 05, 08, 09, 26, 30 (4.7), 06, 49, 308 (4.8), $02,12,13,15,47,78,99,113,127,131,133,174,176,178,187,258,286,293(4.9), 59,107,180,235(4.10), 14,71,79,106,141$, $179,189,215,228,229,246,247$ (4.11), 68 (5.1), 38, 39, 40, 51, 53, 54, 55, 61, 64, 70,77,87, 103, 111, 121, 122, 123, 125, 146, 151, 194, 199, 221, 265, 271, 292, 306, 309 (5.2), 243 (5.4), 89, 284 (5.5), 21 (5.8), 25, 42, 102, 307 (5.9), 61, 73, 81, 116, 173, 183, 184, $185,238,263,264,266,274,282,283(6.1), 88,175,198,250,259,260,267,269,273,276,284(6.2), 42,75,119,216,263,318(7.1)$ $16,33,186,208,216,236,313,314(7.2), 42,43,63,66,75,86,89,132,254,319(8), 334(9), 63,109,264,277(10.1), 67,92,208$, $215,218,220,226,239,243,275,281(10.2), 24,36(11.1), 240(11.2), 62,64,85,105,118,129,172,211,219,225,231,251,264$, 270 (11.3), 01, 46, 300, 301, 302, 310, 323, 324, 325, 326, 327, 328,329 (12), 302 (13) 63, 75, 86, 107, 252, 297, 298, 299, 312, 317 (14); Susim, V. 1147 (4.7); Villar, J. 46, 49, 56,57 60, 61, 63, 78 (5.3). 